\title{
Infra-low Frequency Transcranial Magnetic Stimulation Effectively Improves the Motor Function in Children with Spastic Cerebral Palsy
}

\author{
Junyan Feng, Lin Du, Ling Shan, Bing Wang, Honghua Li, Wei Wang and Feiyong Jia*
}

Division of Pediatric Neurorehabilitation, Department of Pediatrics, The First Hospital of Jilin University, China

*Corresponding author: Feiyong Jia, MD, Associate professor, Master's supervisor, Division of Pediatric Neurorehabilitation, Department of Pediatrics, The First Hospital of Jilin University, Changchun 130021,Jilin Province, China, Tel: 86 15243127876; E-mail: fengjunyan525@163.com

Received date: March 17, 2015; Accepted date: May 01, 2015; Published date: May 05, 2015

Copyright: $@ 2015$ Feng J et al. This is an open-access article distributed under the terms of the Creative Commons Attribution License, which permits unrestricted use, distribution, and reproduction in any medium, provided the original author and source are credited.

\begin{abstract}
Background: Cerebral palsy (CP) is one of the major diseases that lead to severe disability and seriously impacts the quality of life of children. Infra-low frequency transcranial magnetic stimulation (ILF-TMS) is a new technique of noninvasive brain stimulation that exactly regulates the power of specific neurotransmitters through a special magnetic field. Our study was in order to investigate the efficacy of ILF-TMS treatment in children with spastic cerebral palsy.

Methods: 113 spastic cerebral palsic children were randomly divided into two groups: conventional rehabilitation group and ILF-TMS treatment group, Healthy control group was established at the same time. In conventional rehabilitaion group, children were treated with conventional rehabilitation treatment; In ILF-TMS treatment group were treated with ILF-TMS in addition to conventional rehabilitation treatment. Neurotransmitter in the brain was recorded with encephalofluctuograph (EFG) before and after ILF-TMS treatment. Gross Motor Function Measure (GMFM), Fine Motor Function Measure (FMFM) and Gesell development scale (GDS) were used to comprehensively evaluate the motor function in children with spastic cerebral palsy.
\end{abstract}

Results: The results showed that the relative power of $y$-aminobutyric acid (GABA) in spastic cerebral palsy was lower than that in healthy controls and was increased significantly after ILF-TMS treatment for 3 months. The relative power of glutamate (Glu) in spastic cerebral palsy was higher than that in healthy controls and was reduced significantly after ILF-TMS treatment for 3 months. After 3 months training period there was significant improvements on the GMFM (dimension B, dimension C and dimension D), FMFM (dimension A and dimension B) and GDS (gross motor DA and gross motor DQ) in the ILF-TMS treatment group when compared to conventional rehabilitation group.

Conclusions: These findings indicate that GMFM is a sensitive indicator to assess the treatment efficacy in children with spastic cerebral palsy and ILF-TMS treatment can improve the motor function through regulating neurotransmitters in brain.

Keywords: Spastic cerebral palsy; Infra-low frequency transcranial magnetic stimulation; $\gamma$-aminobutyric acid; Glutamate; Gross motor function measure; Fine motor function measure

\section{Abbreviations \\ Ach: Acetylcholine; CP: Cerebral Palsy; DA: Dopamine; EFG: Encephalofluctuograph; FMFM: Fine Motor Function Measure; GMFM: Gross Motor Function Measure; GDS: Gesell Development Scale; Glu: Glutamate; 5-HT: 5-Hydroxytryptamine Amine; ILF-TMS: Infra-low Frequency Transcranial Magnetic Stimulation; NE: Norepinephrine; rTMS: Repetitive Transcranial Magnetic Stimulation; GABA: $\gamma$-Aminobutyric Acid \\ Introduction \\ Cerebral palsy $(\mathrm{CP})$ is defined as a permanent disorder of the development of movement and posture, causing activity limitations that are attributed to non-progressive disturbances that occurred in the developing fetal or infant brain [1-3].}

The motor disorders of cerebral palsy are often accompanied by disturbances of speech disorders, visual, sensation, perception, cognition, communication, and behaviour, by epilepsy and by muscle contraction and deformity of limbs [4-13]. With the development of the perinatology and the improved techniques of neonatal intensive unitthe neonatal mortality is reduced significantly, however, the incidence of $\mathrm{CP}$ has a tendency to increasement in recenty years $[5,14,15]$. CP can be classified as spastic, dyskinetic, ataxic, tonic and atonic types according to clinical characteristics $c$ and spastic type accounts for $70 \%$ children with CP [16,17].

$\mathrm{CP}$ is one of the major diseases that lead to severe disability and seriously impacts the quality of life of children $[7,11,12]$. In addition to motor function, the level of intelligence structure is commonly an important factor to influence the quality of life in children with cerebral palsy $[9,10,13]$. The purpose of cerebral palsy management is not only to ameliorate the body morphology and motor function but also to improve the cognitive ability in patient with CP. Although it is timely and debilitated, conventional rehabilitation treatment remains the mainstay for CP therapy at present [18]. 
There is an imbalance of excitatory and inhibitory neurotransmitters in the brain of children with CP $[19,20]$. It has been known that repetitive transcranial magnetic stimulation (rTMS) can modulate cortical excitability by focally stimulating the cortical region and has therapeutic potential in children with dystonia [21-25]. Hummel et al found that an interhemispheric imbalance is evident in children with brain injury, and that rTMS treatment can restore this imbalance [26,27]. Several studies demonstrate that rTMS therapy cam improve the motor function [25-30] and working memroy in patients with stroke $[31,32]$.

Infra-low frequency transcranial magnetic stimulation (ILF-TMS) is a new technique of noninvasive brain stimulation that exactly regulates the power of specific neurotransmitters through a special magnetic field (frequency less than $0.2 \mathrm{~Hz}$, magnetic field intensity: less than 500GZ)[33]. The ILF-TMS maybe more safer than the rTMS due to its low magnetic field intensity [33]. Jianlan $\mathrm{Xu}$ et al. have reported that consecutive ILF-TMS treatment can recovery the power of the neurotransmitter in mouse [33]. We hypothesized that ILF-TMS can restore the imbalanced neurotransmitters in the brain and then improve the motor and cognitive ability of children with CP. In this study, spastic cerebral palsic children were randomly divided into two groups: conventional rehabilitation group and ILF-TMS treatment group. Assessmental parameters such as GMFM, FMFM, GDS and EFG have been used to comprehensively evaluate the efficacy of ILFTMS on intelligence structure and motor function in children with spastic cerebral palsy.

\section{Methods}

\section{Participants}

A total of 113 spastic cerebral palsic children were recruited from Department of pediatric neurology and rehabilitation, First Hospital of Jilin University from May 2014 to September 2014. They were randomly divided into two groups: conventional rehabilitation group $(n=53)$ and ILF-TMS treatment group $(n=60)$. The healthy control group was established at the same time. Neurotransmitters in the brain were recorded by encephalofluctuograph (EFG) in both children with $\mathrm{CP}$ and healthy control before ILF-TMS intervention and then nurotransmitters in the brain were detected repeatedly at timepoints of 1 month and 3 months after ILF-TMS treatment, respectively.

Gross Motor Function measurement (GMFM), Fine Motor Function measurement (FMFM) and Gesell development scale (GDS) were used to comprehensively evaluate the intelligence domains and motor function in children between conventional rehabilitation group and ILF-TMS treatment group. Inclusion criteria for participation in the study included: (1) a diagnosis of spastic cerebral palsy; (2) age between 2 and 4 years; (3) ability to follow simple instructions. Exclusion criteria included: (1) debilitating illness before or during the study; (2) surgical procedure during, or up to one year prior to the study; (3) Botunum toxin injection Or baclofen intrathecal pump during or up to six months prior to the study; and (4) inability to follow commands. All the children and their parents or caregivers provided their written consent for their participation in this study, and this study was approved by the ethic committee of the first hospital of Jilin universtity. The trial registration number is ChiCTRTRC-14004706.

\section{Method}

Children in the conventional rehabilitation group $(n=53)$ were only Trained by conventional rehabilitation treatment (physical therapy, occupational therapy, speech therapy, chinese massage, hyperbaric oxygen and so on; once a day, 30 minutes every time for one item). Children in the ILF-TMS treatment group $(n=60)$ were undergone with both conventional rehabilitation treatment and ILF-TMS treatment (once a day, 30 minutes every time, frequence: less than 0.2 $\mathrm{Hz}$, magnetic field intensity: less than 500GZ). The main treatment parameters: $\gamma$-aminobutyric acid (GABA), Glutamate (Glu). Adjuvant treatment parameters: 5-hydroxytryptamine amine (5-HT), acetylcholine $(\mathrm{ACh})$, norepinephrine (NE), and dopamine (DA). Neurotransmitters in the brain were recorded by EFG (Kangli-tech company limited, Shenzhen, China) at timepoints before and after ILF-TMS treatment for 1month and 3 months respectively. According to the result of EFG to set the parameters for treatment, using GMFM, FMFM and GDS to do comprehensive evaluation on the two groups before and after treatment for 1 month and 3 months. The GMFM, FMFM and GDS are reliable tools for assessing the motor function and intelligence structure of children with CP. GMFM is a referenced test developed and validated to examine gross motor function skills in children with cerebral palsy and measure changes as a result of intervention [34]. Evidence of the validity and reliability of the GMFM for use in children with cerebral palsy has been extensively established $[35,36]$. Fine motor function measurement is an important item that can reflect the level of development of fine motor function in cerebral palsic children. Wei Shi et al reported that the reliability, validity and responsiveness of the FMFM and the fine motor functioning of children with cerebral palsy could be effectively measured using the FMFM scale $[37,38]$. Gesell developmental scale is an instrument to evaluate the level of infant and toddler mental development though the developmental quotient (DQ) to reflect the mature of the neuromotor integrity and function and to reflect the potential of intellectual development.

\section{Statistical Analysis}

The data were expressed as median and range. The difference between groups was analyzed by the Friedman test using the SPSS16.0 software. A two-side $\mathrm{P}$ value of $<0.05$ was considered statistically significant.

\section{Results}

\section{The demographic and clinical characteristics of the study participants}

To detect the neurotransmitters between spastic cerebral palsyic children and healthy control, 113 spastic cerebral palsic children and 20 healthy controls were recruited in this study. There is a significant difference in gestational age and birth weight between the two groups, other difference about the demographic and clinical characteristics between the spastic cerebral palsic children and health control was not found (Table 1).To determine the effects of ILF-TMS treatment on the intelligence structure and motor function in children with spastic cerebral palsy, 113 spastic cerebral palsic children were randomly divided into two groups: conventional rehabilitation $\operatorname{group}(\mathrm{n}=53)$ and ILF-TMS treatment group $(n=60)$. There was no significant difference about the demographic and clinical characteristics between the two groups (Table 2). 
Citation: Feng J, Du L, Shan L, Wang B, Li H, et al. (2015) Infra-low Frequency Transcranial Magnetic Stimulation Effectively Improves the Motor Function in Children with Spastic Cerebral Palsy . J Neurol Neurophysiol 6: 291. doi:10.4172/2155-9562.1000291

Page 3 of 7

\begin{tabular}{|l|l|l|}
\hline Parameters & $\begin{array}{l}\text { Spastic } \\
\text { cerebral } \\
\text { palsic } \\
\text { children }\end{array}$ & Healthy control \\
\hline Number of Participants & 113 & 23 \\
\hline Age (months) & $41.34 \pm 5.27$ & $39.28 \pm 3.39$ \\
\hline gestational age(months) & $35 \pm 1.21^{*}$ & $38 \pm 1.25$ \\
\hline Sex & 7869.03 & 1669.57 \\
\hline Male\% & 3530.97 & 730.43 \\
\hline Female\% & $27.45 \pm 1.23$ & $26.34 \pm 3.24$ \\
\hline Age of the mother at birthyears & $28.53 \pm 1.87$ & $28.23 \pm 2.87$ \\
\hline Age of the father at birth years & $2.7 \pm 0.4^{*}$ & $3.3 \pm 0.2$ \\
\hline Birth weight $(\mathrm{kg})$ & & \\
\hline
\end{tabular}

Table 1: The demographic of spastic cerebral palsic children and healthy control ${ }^{*} \mathrm{P}<0.05$

\begin{tabular}{|l|l|l|}
\hline Parameters & $\begin{array}{l}\text { Conventional } \\
\text { rehabilitation group }\end{array}$ & $\begin{array}{l}\text { ILF-TMS Treatment } \\
\text { group }\end{array}$ \\
\hline Number of Participants & 53 & 60 \\
\hline Age (months) & 41.849 .58 & 40.846 .93 \\
\hline gestational age(months) & 361.11 & 352.12 \\
\hline Sex & & \\
\hline Male\% & 3566.04 & 4371.67 \\
\hline Female\% & 1833.96 & 1728.33 \\
\hline $\begin{array}{l}\text { Age of the mother at } \\
\text { birthyears }\end{array}$ & 27.543 .24 & 27.365 .25 \\
\hline $\begin{array}{l}\text { Age of the father at } \\
\text { birthyears }\end{array}$ & 28.182 .68 & 28.933 .19 \\
\hline Birth weight (kg) & 2.60 .5 & 2.80 .3 \\
\hline Delivery type\% & 1533.96 & 1220 \\
\hline Natural childbirth & 1528.3 & 4880 \\
\hline Cesarean section & 3871.7 & 3863.33 \\
\hline History of birth asphyxia & & 2236.67 \\
\hline No\% & 3566.04 & 1016.67 \\
\hline Yes\% & 4381.13 & \\
\hline $\begin{array}{l}\text { History of pathologic } \\
\text { jaundice after birth }\end{array}$ & 1018.87 & \\
\hline No\% & & \\
\hline Yes\% & & \\
\hline
\end{tabular}

Table 2: The demographic of conventional rehabilitation group and ILF-TMS treatment group
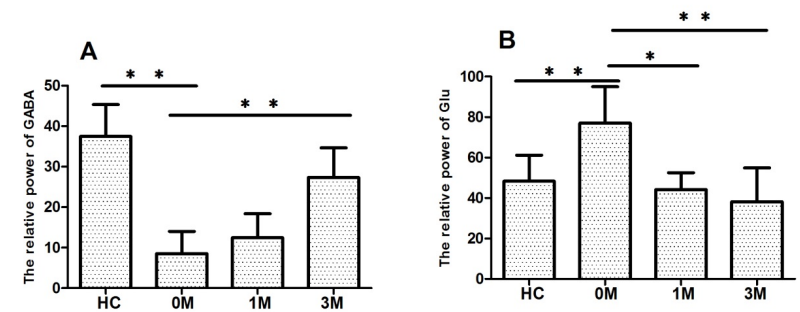

Figure 1: The relative power of GABA and Glu; (A) The changes of relative power of GABA in spastic cerebral palsy after ILF-TMS treatment for 3 months. (B) The changes of relative power of glutamate in spastic cerebral palsy after ILF-TMS treatment for 3 months $\left({ }^{*} \mathrm{P}<0.05,{ }^{* *} \mathrm{P}<0.01\right)$.

\section{The results of gross motor function were assessed by the GMFM}

Gross motor function was assessed using the GMFM. No significant difference in the demographic data and pre-training baseline measures between two groups was found. We analyzed GMFM scores at each of the five dimensions for each child at timepoints as before, 1 month and 3 months after treatment, respectively.

The GMFM scores at each of the five dimensions (dimension A: Lying/rolling, dimension B: Sitting, dimension C: Crawling/kneeling, dimension D: Standing, dimension E: Walking/running/jumping) and total scores had an increasing tendency during the treatment in these two groups, however the improvement of gross mobility function in ILF-TMS treatment group was better than that in conventional rehabilitation group. The results indicated there was a significant difference in the scores in ILF-TMS treatment group compared to the conventional rehabilitation group for dimension $\mathrm{B}$ after treatment for 1 month $(\mathrm{P}<0.05)$ (Figure $2 \mathrm{~A})$. Three months after training period significant improvement in ILF-TMS treatment group for dimension $\mathrm{B}(\mathrm{P}<0.05)$, dimension $\mathrm{C}(\mathrm{P}<0.05)$ and dimension $\mathrm{D}(\mathrm{P}<0.05)$ of the GMFM was found compared to conventional rehabilitation group (Figure 2B and 2C). 
Citation: Feng J, Du L, Shan L, Wang B, Li H, et al. (2015) Infra-low Frequency Transcranial Magnetic Stimulation Effectively Improves the Motor Function in Children with Spastic Cerebral Palsy . J Neurol Neurophysiol 6: 291. doi:10.4172/2155-9562.1000291

Page 4 of 7

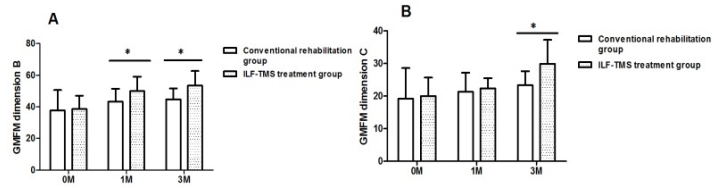

c

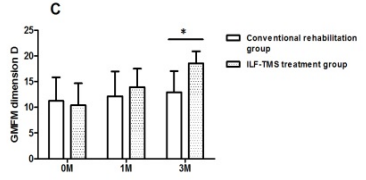

Figure 2: Results of Gross motor function assessed by GMFM in ILF-TMS group and conventional rehabilitation group (A) The changes of dimension $\mathrm{B}$ in GMFM in ILF-TMS group and conventional rehabilitation group (B) The changes of dimension $\mathrm{C}$ in GMFM in ILF-TMS group and conventional rehabilitation group (C) The changes of dimension D in GMFM in ILF-TMS group and conventional rehabilitation group $\left({ }^{*} \mathrm{P}<0.05\right)$.

\section{The results of fine motor function were assessed using the FMFM}

Fine motor function was assessed using the FMFM. No significant difference in the demographic data or pre-training baseline measures between two groups was found. We analyzed FMFM scores at each of the five dimensions for each child before and after treatment.

The FMFM scores at each of the five dimensions (dimension A: visual tracking, performance, dimension E: Coordination ability between hands and eyes) and fine motor ability score had an increasing tendency during the treatment in these two groups. Furthermore, the improvement of fine mobility function in LIF-TMS treatment group was better than in conventional rehabilitation group. Moreover, no significant difference was found 1 month after treatment between the two groups. The results indicated that there was an significant differences in the scores in ILF-TMS treatment group when compared to the conventional rehabilitation group for dimension A and dimension $\mathrm{B} 3$ months after treatment $(\mathrm{P}<0.05$, respectively, Figure $3 \mathrm{~A}$ and $3 \mathrm{~B}$ ).
A

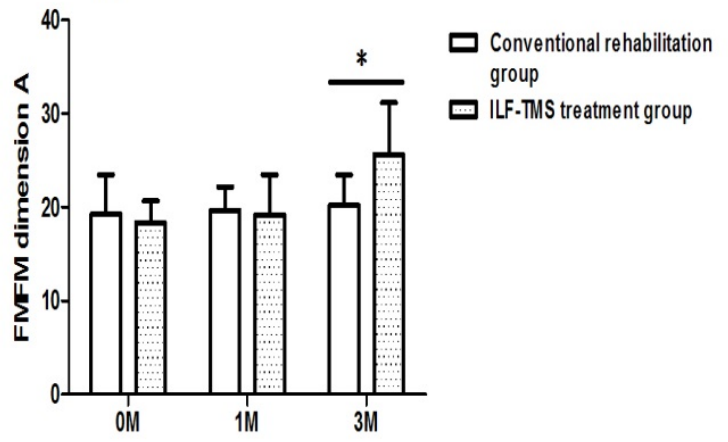

B

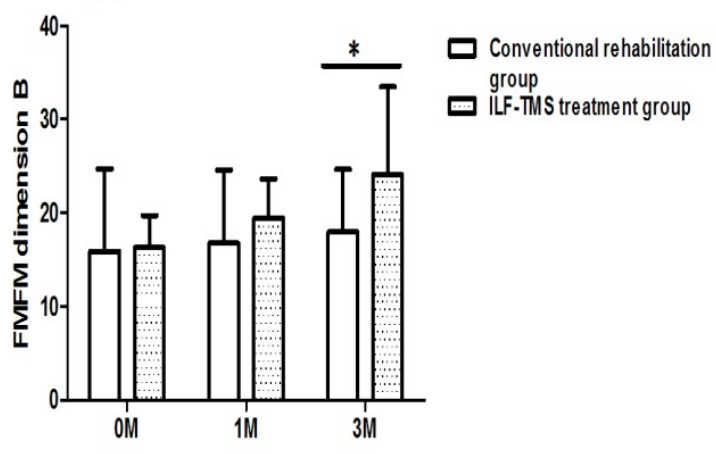

Figure 3: Results of Gross motor function assessed by FMFM in ILF-TMS group and conventional rehabilitation group (A) The changes of dimension A in GMFM in ILF-TMS group and conventional rehabilitation group (B) The changes of dimension B in GMFM in ILF-TMS group and conventional rehabilitation group $\left({ }^{*} \mathrm{P}<0.05\right)$

\section{The results of Intelligence structure were assessed by the GMFM}

Intelligence structure was assessed using the GDS. No significant difference in the demographic data or pre-training baseline measures between the two groups was found. We analyzed the GDS scores at each of the five domains for each child before and after treatment.

The GDS scores at each of the five domains (domain A: Gross motor DA/DQ, domain B: Fine motor DA/DQ, domain C: object adaptive ability $\mathrm{DA} / \mathrm{DQ}$, domain $\mathrm{D}$ : Speaking $\mathrm{DA} / \mathrm{DQ}$, domain $\mathrm{E}$ : personalsocial behavior $\mathrm{DA} / \mathrm{DQ}$ ) had an increasing trend after treatment in two groups. The results indicated that there was a significant differences in the scores in LIF-TMS treatment group compared to conventional rehabilitation group for gross motor DA and gross motor DQ 3 months after treatment $(\mathrm{P}<0.05$, respectively, Figures $4 \mathrm{~A}$ and $4 \mathrm{~B})$. However, no difference about domain $\mathrm{B}$, domain $\mathrm{C}$ and domain $\mathrm{D}$ was found between two groups. 
A

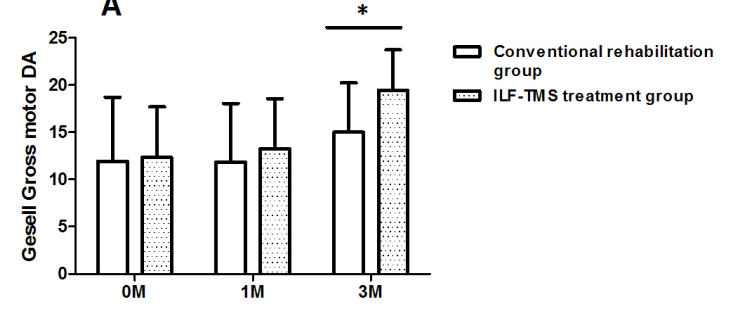

B

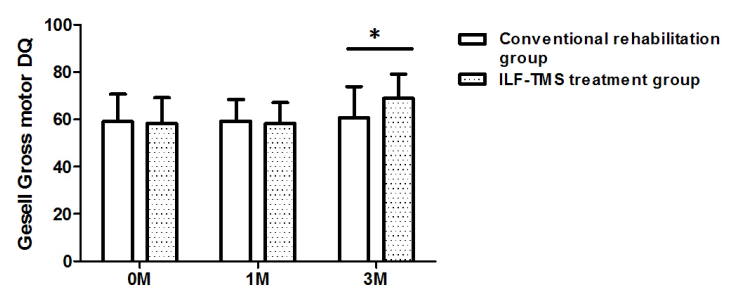

Figure 4: Results of intelligence structure assessed by GDS in ILF-TMS group and conventional rehabilitation group (A) The changes of gross motor DA in GDS in ILF-TMS group and conventional rehabilitation group (B) The changes of gross motor DQ in GDS in ILF-TMS group and conventional rehabilitation group $\left({ }^{*} \mathrm{P}<0.05\right)$.

\section{Discussion}

The main findings in this study are: 1. the relative power of GABA in spastic cerebral palsy is lower than that in healthy controls and is increased significantly after ILF-TMS treatment for 3 months; the relative power of glutamate in spastic cerebral palsy is higher than that in healthy controls and is reduced significantly after ILF-TMS treatment for 3 months. 2. ILF-TMS treatment has improved the performance of CP children on GMFM and FMFM.

Preterm infants markedly increase the risk of CP. Studies examined risk factors in preterm infants [39-41]. Risk factors classically associated with $\mathrm{CP}$ in term infants such as preeclampsia, male gender, neonatal sepsis and Apgar scores were less important in preterm infants. Absence of antenatal steroids, growth restriction, and adverse events in the newborn period such as prolonged hypocarbia and postnatal steroids assume greater importance.

CP plays a serious burden to the individual family and society. Children and their families require significant additional support from medical, educational and social systems. The most important treatment at present for CP is timely, long-term, standardized rehabilitation training. Our research has shown that comprehensive rehabilitation can improve the development quotient and five domains including gross motorfine motoradaptationlanguage and individualsocial domains. This demonstrates that conventional rehabilitation is still an important method for treatment of cerebral palsy [42].

GABA and glutamate are the two basic neurotransmitters in the brain in the mammalian central nervous system [43-46]. GABA is not only functionally but also metabolically linked with its excitatory counterpart glutamate, as glutamine is the precursor of both. GABA and glutamate, once released from neurons, are taken up into astrocytes, which convert glutamate into glutamine. Impairments of these glial-neuronal interactions result in nervous system diseases[47,48]. They were closely related with advanced functions such as memory, learning and cognition.

The results have shown that the relative power of GABA in brain in spastic cerebral palsy was lower than that in healthy controls and the relative power of Glutamate was higher than that of healthy controls. The changes of GABA and glutamate recorded with EFG in CP children are consistent with previous studies [49-53]. In this study, we use the conventional rehabilitation treatment combined with ILF-TMS treatment on spastic cerebral palsy. Neurotransmitter in the brain was recorded with EFG. We use the ILF-TMS treatment to improve the balance between GABA and Glu in the spastic cerebral palsic children. The relative power of GABA in spastic cerebral palsy was increased and Glu was reduced significantly after ILF-TMS treatment for 3 months. We think that ILF-TMS can regulate the function of neurotransmitter by a specific magnetic field generated in the brain. ILF-TMS has been reported in the central nervous system diseases widely [54,55].

Several reports have demonstrated that low frequency rTMS facilitates the recovery of motor function in children with a brain injury, suggesting that rTMS is a useful modality to improve the motor in disable patient due to cerebral impairment [56,57]. However, no paper about the effect of ILF-TMS treatment on the changes of motor function in spastic cerebral palsy has been reported. In this study, we use A battery of instruments such as of GMFM, FMFM and GDS to comprehensively evaluate the performance of $\mathrm{CP}$ children treated with ILF-TMS treatment. Analysis of the scores in the three tasks indicates that the children treated with ILF-TMS have performed better than those in the conventional rehabilitation group. To the best of our knowledge, this is the first report that ILF-TMS treatment can restore the balance of neurotransmitters such as GBAB and glutamate and improve the motor function and intelligence in children with $\mathrm{CP}$. We deduce that ILF-TMS treatment maybe improve the intelligence structure and motor function in $\mathrm{CP}$ children through regulating neurotransmitters in brain.

There are some shortcomings of our present study such as small samples and short-term ILF-TMS intervention. A further larger sample and long-term study for ILF-TMS treatment for CP children is warranted. Above all, the present study has shown that ILF-TMS is effective in improve the motor function and maybe is a worthwhile choice in the treatment for CP children.

\section{Acknowledgements}

We thank all the children who were participated in our study and their parents and/or caregiver's support and Kangli-tech company limited (Shenzhen, China) who provided Ultra-low frequency transcranial magnetic stimulator. 


\section{References}

1. Keen JR, Przekop A, Olaya JE, Zouros A, Hsu FP (2014) Deep brain stimulation for the treatment of childhood dystonic cerebral palsy. Neurosurg Pediatr 14: 585-593.

2. Bax M, Goldstein M, Rosenbaum P, Leviton A, Paneth N (2005) Proposed definition and classification of cerebral palsy, Developmental Medicine and Child Neurology April 47: 571-576.

3. Sharifi A, Kamali M, Chabok A (2014) Rehabilitation Needs of People with Cerebral Palsy: a qualitative Study. Med J Islam Repub Iran 28: 16.

4. Rosenbaum P, Paneth N, Leviton A, Goldstein M, Bax M, et al. (2007) A report: the definition and classification of cerebral palsy April 2006. Dev Med Child Neurol Suppl 109: 8-14.

5. Odding E, Roebroeck ME, Stam HJ (2006) The epidemiology of cerebra palsy: incidence, impairments and risk factors. Disabil Rehabil 28 : 183-191.

6. Oriady Zanjani, M (2005) Cerebral palsy in viewpoint of speechlanguage pathology nature, assessment and treatment. Hamedan: Noore elm Publications.

7. Akhundian J (2003) Epilepsy in children with cerebral palsy. Children disease of Iran. Mashhad University of Medical Sciences. Imam Reza hospital. Department of Pediatrics. Twelfth year 3: 21-25.

8. Shevell MI, Dagenais L, Hall N; REPACQ Consortium (2009) Comorbidities in cerebral palsy and their relationship to neurologic subtype and GMFCS level. Neurology 72: 2090-2096.

9. Seif Workinger M (2009) Cerebral Palsy Resource Guide for SpeechLanguage Pathologists. Translated by Zamani p \& Mousavi N. Tehran: Danzhh.

10. Oriadi Zanjani M. Cerebral palsy from the standpoint of, speech and language pathology. Nature, assessment and treatment. Hamadan: Nore elm Publishers. [In Persian].

11. Ameri E, Yeganeh A (2008) Prevalence of foot deformity in cerebral palsy patients in 3 to 20 years old to referring Shafa Yahyaeian in Tehran. Journal of Hamadan University of Medical Sciences and Health Services 14: 43 : $34-38$

12. Khayatzadeh Mahany M, Amirsalari S, Karimloo M (2012) Accompanying Problems in Children with Cerebral Palsy and their Relationship to type and Level of Motor Disability. Medical scientific Journal of Gondi Shapoor of Ahvaz 10: 59-67.

13. Sarvestani Bigham M (2006) Cerebral palsy theories, Techniques treatments. Tehran: Danzhh 106.

14. El-Tallawy HN, Farghaly WM, Shehata GA, Rageh TA, Metwally NA, et al. (2014) Cerebral palsy in Al-Quseir City, Egypt: prevalence, subtypes, and risk factors. Neuropsychiatr Dis Treat 10: 1267-1272.

15. Vincer MJ, Allen AC, Allen VM, Baskett TF, O'Connell CM (2014) Trends in the prevalence of cerebral palsy among very preterm infants (<31 weeks' gestational age). Paediatr Child Health 19: 185-189.

16. Love SC, Novak I, Kentish M, Desloovere K, Heinen F, et al. (2010) Cerebral Palsy Institute. Botulin toxin assessment, intervention and aftercare for lower limb spasticity in children with cerebral palsy: international consensus statement. Eur J Neurol 17: 9-37.

17. Blair E, Watson L, Badawi N, Stanley FJ (2001) Life expectancy among people with cerebral palsy in Western Australia. Dev Med Child Neurol 43: 508-515.

18. Mao YL, Jia FY, Hu XL (2009) Early diagnosis and treatment of cerebral palsy.Zhongguo Fuyou Baojian 24: 1235-1236.

19. Ng J, Heales SJ, Kurian MA (2014) Clinical features and pharmacotherapy of childhood monoamine neurotransmitter disorders. Paediatr Drugs 16: 275-291.

20. Drobyshevsky A, Takada SH, Luo K, Derrick M, Yu L, et al. (2015) Elevated spinal monoamine neurotransmitters after antenatal hypoxiaischemia in rabbit cerebral palsy model. J Neurochem 132: 394-402.

21. Kodama M, Kasahara T, Hyodo M, Aono K, Sugaya M, et al. (2011) Effect of low-frequency repetitive transcranial magnetic stimulation combined with physical therapy on L-dopa-induced painful off-period dystonia in Parkinson's disease. Am J Phys Med Rehabil 90:150-155.

22. Tyvaert L, Houdayer E, Devanne H, Monaca C, Cassim F, et al. (2006) The effect of repetitive transcranial magnetic stimulation on dystonia: a clinical and pathophysiological approach. Neurophysiol Clin 36: 135-143.

23. Lefaucheur JP, Fenelon G, Menard-Lefaucheur I, Wendling S, Nguyen JP (2004) Low-frequency repetitive TMS of premotor cortex can reduce painful axial spasms in generalized secondary dystonia: a pilot study of three patients. Neurophysiol Clin 34: 141-145.

24. Murase N, Rothwell JC, Kaji R, Urushihara R, Nakamura K, et al. (2005) Subthreshold low-frequency repetitive transcranial magnetic stimulation over the premotor cortex modulates writer's cramp. Brain 128: 104-115.

25. Alonso-Alonso M, Fregni F, Pascual-Leone A (2007) Brain stimulation in poststroke rehabilitation. Cerebrovasc Dis 24 Suppl 1: 157-166.

26. Hummel F, Celnik P, Giraux P, Floel A, Wu WH, et al. (2005) Effects of non-invasive cortical stimulation on skilled motor function in chronic stroke. Brain 128: 490-499.

27. Hummel FC, Cohen LG (2006) Non-invasive brain stimulation: a new strategy to improve neurorehabilitation after stroke? Lancet Neurol 5: 708-712.

28. Fregni F, Boggio PS, Mansur CG, Wagner T, Ferreira MJ, et al. (2005) Transcranial direct current stimulation of the unaffected hemisphere in stroke patients. Neuroreport 16: 1551-1555.

29. Jang SH, Ahn SH, Byun WM, Kim CS, Lee MY, et al. (2009) The effect of transcranial direct current stimulation on the cortical activation by motor task in the human brain: an fMRI study. Neurosci Lett 460: 117-120.

30. Profice P, Pilato F, Dileone M, Ranieri F, Capone F, et al. (2007) Use of transcranial magnetic stimulation of the brain in stroke rehabilitation. Expert Rev Neurother 7: 249-258.

31. Fregni F, Boggio PS, Nitsche M, Bermpohl F, Antal A, et al. (2005) Anodal transcranial direct current stimulation of prefrontal cortex enhances working memory. Exp Brain Res 166: 23-30.

32. Jo JM, Kim YH, Ko MH, Ohn SH, Joen B, et al. (2009) Enhancing the working memory of stroke patients using tDCS. Am J Phys Med Rehabil 88: 404-409.

33. Jianlan $\mathrm{Xu}$, Xiaoxue Xu, Qing Cai (2010) Influence of repeatedly ?aminobutyric acid and dopamine characteristic repetitive ultra-lowfrequency transcranial magnetic stimulation in rat brain neurotransmitter power. Zhongguo Kangfu Yixue Zazhi 25: 127-130.

34. Russell DJ, Rosenbaum PL, Cadman DT, Gowland C, Hardy S, et al. (1989) The gross motor function measure: a means to evaluate the effects of physical therapy. Dev Med Child Neurol 31: 341-352.

35. Bjornson K, Graubert C, McLaughlin J (2000) Test-retest reliability of the gross motor function measure in children with cerebral palsy. Pediatr Phys Ther 12: 200-202.

36. Russell DJ, Avery LM, Rosenbaum PL, Raina PS, Walter SD, et al. (2000) Improved scaling of the gross motor function measure for children with cerebral palsy: evidence of reliability and validity. Phys Ther $80: 873-885$.

37. Wei Shi, Hui Li, Sujuan Wang (2006) Psychometric properties of the fine motor function measure scale for children with cerebral palsy. Zhongguo Wuli Yixue yu Kangfu Zazhi 28: 320-323.

38. Wei Shi, Hui Li, Sujuan Wang (2005) Developing the fine motor function measure scake by rasch anakysis for children with cerebral palsy. Zhongguo Wuli Yixue yu Kangfu Zazhi 5: 289-290.

39. Tran U, Gray PH, O'Callaghan MJ (2005) Neonatal antecedents for cerebral palsy in extremely preterm babies and interaction with maternal factors. Early Hum Dev 81: 555-561.

40. Takahashi R, Yamada M, Takahashi T, Ito T, Nakae S, et al. (2005) Risk factors for cerebral palsy in preterm infants. Early Hum Dev 81: 545-553.

41. Livinec F, Ancel PY, Marret S, Arnaud C, Fresson J, et al. (2005) Prenatal risk factors for cerebral palsy in very preterm singletons and twins. Obstet Gynecol 105: 1341-1347.

42. Chen YN, Liao SF, Su LF, Huang HY, Lin CC, et al. (2013) The effect of long-term conventional physical therapy and independent predictive 
Citation: Feng J, Du L, Shan L, Wang B, Li H, et al. (2015) Infra-low Frequency Transcranial Magnetic Stimulation Effectively Improves the Motor Function in Children with Spastic Cerebral Palsy . J Neurol Neurophysiol 6: 291. doi:10.4172/2155-9562.1000291

Page 7 of 7

factors analysis in children with cerebral palsy. Dev Neurorehabil 16 357-362.

43. Cousijn H, Haegens S, Wallis G, Near J, Stokes MG, et al. (2014) Resting GABA and glutamate concentrations do not predict visual gamma frequency or amplitude. Proc Natl Acad Sci U S A 111: 9301-9306.

44. Ohkawa T, Satake S, Yokoi N, Miyazaki Y, Ohshita T, et al. (2014) Identification and characterization of $\mathrm{GABA}(\mathrm{A})$ receptor autoantibodies in autoimmune encephalitis. J Neurosci 34: 8151-8163.

45. Hattingen E, Lückerath C, Pellikan S, Vronski D, Roth C, et al. (2014) Frontal and thalamic changes of GABA concentration indicate dysfunction of thalamofrontal networks in juvenile myoclonic epilepsy. Epilepsia 55: 1030-1037.

46. Dumans'ka HV, Rykhal's'kyÄ OV, Veselovs'kyÄ MS (2014) [Characteristics of quantal release of glutamate and GABA in synapses between retinal ganglion cells and superior colliculus neurons in coculture]. Fiziol Zh 60: 3-10.

47. Bak LK, Schousboe A, Waagepetersen HS (2006) The glutamate/GABAglutamine cycle: aspects of transport, neurotransmitter homeostasis and ammonia transfer. J Neurochem 98: 641-653.

48. Eid T, Ghosh A, Wang Y, Beckström H, Zaveri HP, et al. (2008) Recurrent seizures and brain pathology after inhibition of glutamine synthetase in the hippocampus in rats. Brain 131: 2061-2070.

49. Hattingen E, Lückerath C, Pellikan S, Vronski D, Roth C, et al. (2014) Frontal and thalamic changes of GABA concentration indicate dysfunction of thalamofrontal networks in juvenile myoclonic epilepsy. Epilepsia 55: 1030-1037.
50. Yuan HB, Cheng LY, Yin F, Zhang GX, Peng J, et al. (2008) [Levels of amino acids in cerebral spinal fluid in children with cerebral palsy]. Zhongguo Dang Dai Er Ke Za Zhi 10: 475-477.

51. Xin Zhang, Peng Xu, Daguang Zhang, Jiting Zhang (2002) Study on excitement and inhibitory amino acids and acetylcholinesterase in the cerebrospinal fluid of children with spastic cerebral palsy. Zhongguo Linchuang Kangfu 6: 349-350.

52. Peng $\mathrm{Xu}$, Yi Zhao, Xin Zhang (2004) Change of amino acid neurotransmitter in cerebrospinal fluid in children with cerebral palsy. Jilin Daxue Xuebao 30: 117-119.

53. Fenglian Zhu, Jin Li, Huiyin Qian (2004) Glutamate and?-aminobutyric acid in the cerebrospinal fluid of children with spastic cerebral palsy. Zhongguo Linchuang Kangfu. 8: 8341-8347.

54. Guodong Li, Wangsong Zhou, Liwen Guo (1993) Bio-magnetismapplication of technical principles.Beijing: Guofang Gongye Chuban She $107-253$

55. Wansong Zhou (1990) Research development of domestic field biological effects. Zhongguo Wuli Yixue Zazhi 12:118-120.

56. Hsu WY, Cheng CH, Liao KK, Lee IH, Lin YY (2012) Effects of repetitive transcranial magnetic stimulation on motor functions in patients with stroke: a meta-analysis. Stroke 43: 1849-1857.

57. Kim L, Chun MH, Kim BR, Lee SJ (2011) Effect of repetitive transcranial magnetic stimulation on patients with brain injury and Dysphagia. Ann Rehabil Med 35: 765-771. 